\title{
E2F-1 Transcription Factor Is Overexpressed in Oxyphilic Thyroid Tumors
}

Marco Volante, M.D., Sabrina Croce, M.D., Carla Pecchioni, B.Sc., Mauro Papotti, M.D. Department of Biomedical Sciences and Oncology, University of Turin, Torino, Italy

In thyroid tumors, several cell cycle regulators have been found to be altered or overexpressed, but no data exist on E2F transcription factors. Such factors (E2F-1 in particular) act as the final effectors in the retinoblastoma pathway but are also involved in apoptosis. To analyze E2F-1 expression in thyroid neoplasms, we investigated 73 thyroid tumors, including 28 oxyphilic and 45 nonoxyphilic lesions, by immunohistochemistry, in parallel with other cell cycle-related proteins (p27, pRb, p53, and Ki67). p27, Ki-67, pRb, and p53 expression patterns generally overlapped the literature data. E2F-1 was expressed in all thyroid tumor types, both benign and malignant, with no statistical correlation with proliferative status (except for anaplastic carcinoma). A significantly higher percentage of tumor cells expressed E2F-1 in oxyphilic adenomas (71.5\%) and oxyphilic carcinomas $(66.1 \%)$ as compared with that of the corresponding nonoxyphilic lesions (30.8\% and $34.5 \%$, respectively; $P<.05)$. These same tumors had a relatively low proliferative index. Therefore, because oxyphilic tumors of the thyroid show peculiar morphological, phenotypic, and ultrastructural features, possibly related to their particular metabolic conditions, it is possible that E2F-1 overexpression is linked to activities other than cell cycle entry in oxyphilic tumors. In conclusion, E2F-1 is expressed in both benign and malignant thyroid tumors, thus suggesting a wide involvement of the retinoblastoma pathway in thyroid tumorigenesis. In addition, in oxyphilic tumors, more than two thirds of tumor cells express E2F-1, an event possibly linked to proapoptotic rather than proliferative signals in such neoplasms.

Copyright () 2002 by The United States and Canadian Academy of Pathology, Inc.

VOL. 15, NO. 10, P. 1038, 2002 Printed in the U.S.A.

Date of acceptance: June 21, 2002.

This work was supported by grants from the Italian Ministry of University (ex $60 \%$ to MP).

Address reprint requests to: Mauro Papotti, M.D., Department of Biomedical Sciences and Oncology, University of Turin, via Santena 7, 10126 Torino, Italy; e-mail: mauro.papotti@unito.it; fax: 39-011-6635267.

DOI: 10.1097/01.MP.0000028645.36632.A8
KEY WORDS: Cell cycle, E2F-1, Immunohistochemistry, Oxyphilic, Retinoblastoma pathway, Thyroid tumors.

Mod Pathol 2002;15(10):1038-1043

Oxyphilic tumors of the thyroid are characterized by cells with an abundant granular eosinophilic cytoplasm, as a consequence of mitochondria accumulation $(1,2)$. Their exact classification has been debated for many years, leading some authors to keep these tumors separate from other follicular neoplasms $(3,4)$. However, recent evidence has indicated that oxyphilic (Hurthle cell, oncocytic) tumors of follicular origin behave as their conventional counterparts and only differ from classical follicular lesions because of their extremely high content of mitochondria $(5,6)$.

The proliferative status and alterations of the cell cycle and retinoblastoma $(\mathrm{Rb})$ pathway in oxyphilic and nonoxyphilic tumors have been assessed in several studies on thyroid cancer (7-21). Several studies on the proliferative activity of oxyphilic tumors demonstrated no differences from conventional follicular adenomas and carcinomas, both well differentiated and poorly differentiated $(10,15$, 22). In one of these studies (10), cyclin D1 was found to be overexpressed in oxyphilic carcinomas as compared with oxyphilic adenomas, as described in nonoxyphilic well-differentiated carcinomas of both follicular and papillary types as well $(7-9,11)$. p27, one of the inhibitors of cyclinedependent kinases, was found to be reduced in thyroid tumors, namely papillary, poorly differentiated, and anaplastic carcinomas $(8,18)$, but had never been extensively investigated in Hurthle cell tumors. Recently (14), the retinoblastoma protein (pRb) was reported by means of immunohistochemistry to be down-regulated in a variety of thyroid tumors, mostly malignant with the notable exception of oxyphilic adenomas, which showed loss of protein expression in $100 \%$ of cases. No studies have been dealing with the final effectors of the $\mathrm{Rb}$ pathway, which involves $\mathrm{Rb}$ phosphorylation on the one side and the E2F transcription factor family activation on the other, in a complex 
molecular mechanism further complicated by recent evidence that both $\mathrm{pRb}$ and E2F-1 possess additional properties on developmental, tumorigenic, and apoptotic processes (23-25). A preliminary report on a member of the latter group (26) indicated that E2F-1 was overexpressed in cases of oxyphilic variant of papillary carcinoma. In tumor pathology, E2F-1 expression recently has been shown to bear prognostic implications in tumors of other locations, including lymphoproliferative disorders (27-29), gastrointestinal carcinomas (30-31), and bladder tumors (32).

Oxyphilic cells and tumors were shown to bear a marked genomic DNA fragmentation by means of in situ end-labeling technique (33). This may be the result of the particular metabolic status of these mitochondrion-rich cells, as suggested by spontaneous or induced (e.g., fine needle aspiration) extensive cell death response to ischemic or stress stimuli in oxyphilic thyroid nodules, whose nature is not fully understood.

The aim of the present study was to analyze a series of oxyphilic thyroid tumors for the immunohistochemical expression of E2F-1, a pivotal molecule between the retinoblastoma pathway leading to cell division, on the one side, and to cell death processes, on the other. We here show that oxyphilic (Hurthle cell) tumors (but not their nonoxyphilic counterparts) express E2F-1 in most tumor cells, in the absence of a high proliferative activity, indicating that E2F-1 may regulate activities other than cell cycle entry in such mitochondrion-rich cells and tumors.

\section{MATERIALS AND METHODS}

\section{Case Selection}

Seventy-three cases of thyroid tumors were selected from the files of the Department of Pathology, University of Turin, between 1990 and 2000. These included 28 oxyphilic tumors and 45 control cases of nonoxyphilic neoplasms. Among the former, there were 8 oxyphilic (Hurthle cell) adenomas (HA); 12 oxyphilic carcinomas (HCC); and 8 papillary carcinomas, oxyphilic variant. In the control group, 6 follicular adenomas (FA), 4 minimally invasive follicular carcinomas (FTC), 11 papillary carcinomas (PTC), 15 poorly differentiated (insular) carcinomas (PDC), and
9 anaplastic carcinomas (AC) were collected. In addition, 3 cases of nodular goiter with oxyphilic changes and 3 cases of Hashimoto thyroiditis were investigated. Most oxyphilic tumors have been included in a previous study on DNA fragmentation by means of the in situ end-labeling technique (33). Formalinfixed paraffin-embedded tissue blocks were available for conventional histology and standard immunohistochemical procedures. Clinicopathological parameters were collected for each case and compared with histological and immunohistochemical findings.

\section{Immunohistochemistry}

Serial sections collected on poly-L-lysine-coated slides were processed for conventional immunohistochemistry after a standard streptavidin procedure. Antigen retrieval in microwave oven (three 5 -min cycles at $750 \mathrm{~W}$ in citrate buffer, $\mathrm{pH}$ 6.0) was performed for all antibodies tested. Accurate blocking of endogenous biotin was obtained, as previously described (34). A list of the antibodies tested, which included antibodies anti-Ki-67, p27 ${ }^{\text {kip1 }}$, E2F-1, pRb, and p53, is reported in Table 1. For E2F-1 and pRb immunostaining, tyramidecatalyzed reporter deposition (CARD) amplification was applied. Biotinylated tyramine was prepared according to Adams (35) and diluted 1/50 to prevent nonspecific background.

\section{Immunohistochemical Evaluation and Controls}

Ki-67, p27, E2F-1, and p53 expression were evaluated as the mean percentage of positive nuclei after counting 1000 cells at high-power field; pRb expression was considered normal (heterogeneous) when a percentage of positive cells between $1 \%$ and $50 \%$ was present, although altered in the absence of staining or in case of overexpression $(>50 \%$ positive nuclei; 36).

Normal peritumoral thyroid served as internal positive controls for $\mathrm{p} 27$ and $\mathrm{pRb}$, and lymphocytic infiltrate, for Ki-67 and E2F-1, respectively. Hyperplastic tonsil sections were also included as positive controls. Negative controls included omission of the primary antibody and incubation with an unrelated antibody (anti-progesterone receptor).

TABLE 1. List of Antibodies Employed

\begin{tabular}{|c|c|c|c|c|c|}
\hline Antibody & Clone & Manufacturer (Location) & Dilution & $\mathrm{AR}$ & CARD \\
\hline Ki-67 & MIB-1 & Immunotech (Marseille, France) & $1 / 10$ & Yes & No \\
\hline $\mathrm{p} 27^{\mathrm{kip} 1}$ & 57 & Transduction (Lexington, KY) & $1 / 1000$ & Yes & No \\
\hline E2F-1 & KH95 & Santa Cruz (Santa Cruz, CA) & $1 / 200$ & Yes & Yes \\
\hline $\mathrm{pRb}$ & IF-8 & Santa Cruz & $1 / 100$ & Yes & Yes \\
\hline p53 & DO-7 & Ylem (Rome, Italy) & $1 / 100$ & Yes & No \\
\hline
\end{tabular}

AR, microwave oven-based antigen retrieval; CARD, catalyzed reporter deposition. 


\section{Statistical Analysis}

The differences in the percentage of every single immunohistochemical parameter were compared among different histotypes by applying the Student's $t$ test corrected according to Bonferroni ( $\alpha=$ 0.05 ; confidence interval, 0.95 ). Rb protein expression was evaluated as the percentage of tumors with altered expression (either total absence or overexpression, i.e., $>50 \%$; 36). Oxyphilic lesions inclusive of HA, HCC, and oxyphilic variant of PTC were grouped together and compared with nonoxyphilic counterparts (Table 2). FAs and HAs were also grouped together (benign tumor group) and compared with well-differentiated follicular carcinomas (FTC and HCC). Clinicopathological parameters (age, gender, pTN status) were compared with different protein expression values by the $\chi^{2}$ test.

\section{RESULTS}

In general, an altered regulation of the Rb pathway was observed in most thyroid tumors investigated. Only 14 cases had an apparently normal profile. All the others had one (28 cases) or, more frequently, two or three (31 cases) parameters altered, irrespective of the tumor type. The results are summarized in Table 2. No immunoreactivity for p27, pRb, p53, E2F-1, and Ki67 was observed in negative control sections.

E2F-1 protein expression was significantly higher in follicular oxyphilic tumors as compared with the group of nonoxyphilic tumors $(P<.05)$. HAs expressed E2F-1 in 71.5\% (range, 37-95\%) of cells (Fig. 1) and HCCs in $66.1 \%$ (range, 26-95\%; Fig. 2). Oxyphilic variant of PTC expressed E2F-1 in $63.1 \%$ (range, 19-95\%) of tumor cells, a value much higher (but below statistical significance) than that of nonoxyphilic PTC. As expected, E2F-1 protein expression was low in normal thyroid as well as in nonneoplastic oxyphilic cells (in nodular goiter or Hashimoto thyroiditis; $24 \%$ ) and progressively increased from FA (30.8\%) to AC (65\%), having well- and poorly differentiated carcinomas intermediate values (FTC, 34.5\%; PTC, 46.7\%; PDC, 34.3\%).

The mean proliferative activity, detected by Ki- 67 immunostaining, was $2.7 \%$ in oxyphilic adenomas and $2.4 \%$ in oxyphilic carcinomas. These figures are overlapping to those observed in the corresponding nonoxyphilic tumor types $(1.5 \%$ and $1.7 \%$, respectively). Significantly higher values were observed in PDC and AC (7.2\% and 52.2\%, respectively). Rb protein abnormal expression (absence or overexpression: see Materials and Methods) was detected in a percentage of cases ranging from $37.5 \%$ in HA to $16.6 \%$ in HCC. In the control group, $\mathrm{Rb}$ was altered in $16.7 \%$ (FA) to $53.3 \%$ (PDC) of the cases, but no statistically significant differences were observed. In negative cases, the presence of scattered positive nuclei in endothelial cells or in peritumoral thyroid follicles served as internal control. Oxyphilic tumors had a mean expression of p27 of $50.2 \%$ in $\mathrm{HA}$ and $73.5 \%$ in $\mathrm{HC}$, a finding overlapping that of the corresponding nonoxyphilic cases. As expected, p27 expression was significantly lower in PTC $(8.9 \%$ in nonoxyphilic and $10.2 \%$ in oxyphilic variants) and $\mathrm{AC}(10.4 \%)$ as compared with all other groups. p53 immunoreactivity was low in HA and HCC. The same happened in well- and poorly differentiated tumors (from $<1 \%$ to $4.1 \%$ ), as opposed to AC, which had a significant increase $(25.3 \%)$.

Clinicopathological correlations were focused on p27, E2F-1, and pRb expression, using the $\chi^{2}$ test. None of these proteins was found to have a significant relation to sex, age, pTN, or biological behavior among any histological type.

\section{DISCUSSION}

The present study is the first description of E2F-1 transcription factor expression in a large series of thyroid tumors, with special reference to oxyphilic tumors. Earlier studies on other tumor types demonstrated a good correlation between immunohistochemical and mRNA detection of E2F-1 (28). We

TABLE 2. E2F-1 Expression in Thyroid Tumors, Compared with Other Cell Cycle-Related Proteins

\begin{tabular}{|c|c|c|c|c|c|c|c|c|c|}
\hline \multirow{2}{*}{ Diagnosis (No. of Cases) } & \multirow{2}{*}{$\begin{array}{l}\text { Sex } \\
(\mathrm{F} / \mathrm{M})\end{array}$} & \multirow{2}{*}{$\begin{array}{c}\text { Age } \\
\text { (Mean in y) }\end{array}$} & \multirow{2}{*}{$\begin{array}{c}\text { Ki-67 } \\
\text { (Mean \%) }\end{array}$} & \multirow{2}{*}{$\begin{array}{c}\mathrm{p} 27 \\
\text { (Mean \%) }\end{array}$} & \multirow{2}{*}{$\begin{array}{c}\text { E2F-1 } \\
\text { (Mean \%) }\end{array}$} & \multicolumn{3}{|c|}{$\mathrm{pRb}$} & \multirow{2}{*}{$\begin{array}{c}\text { p53 } \\
\text { (Mean \%) }\end{array}$} \\
\hline & & & & & & $\%^{a}$ & Negative & Overexpression & \\
\hline Oxyphilic adenoma (8) & $4 / 4$ & 45 & 2.7 & 50.2 & $71.5^{*}$ & 37.5 & $1 / 8$ & $2 / 8$ & $<1$ \\
\hline $\begin{array}{l}\text { Oxyphilic follicular } \\
\text { carcinoma (12) }\end{array}$ & $8 / 4$ & 41.8 & 2.4 & 73.2 & $66.1^{*}$ & 16.6 & $0 / 12$ & $2 / 12$ & $<1$ \\
\hline $\begin{array}{l}\text { Oxyphilic papillary } \\
\text { carcinoma (8) }\end{array}$ & $5 / 3$ & 41.2 & 1.5 & $10.2^{*}$ & 63.1 & 25 & $1 / 8$ & $1 / 8$ & $<1$ \\
\hline Follicular adenoma (6) & $4 / 2$ & 46 & 1.5 & 60.2 & 30.8 & 16.7 & $0 / 6$ & $1 / 6$ & $<1$ \\
\hline Follicular carcinoma (4) & $4 / 0$ & 47.3 & 1.7 & 72.6 & 34.5 & 25 & $0 / 4$ & $1 / 4$ & $<1$ \\
\hline Papillary carcinoma (11) & $8 / 3$ & 50.1 & 3.3 & $8.9 *$ & 46.7 & 27.3 & $1 / 11$ & $2 / 11$ & $<1$ \\
\hline $\begin{array}{l}\text { Poorly differentiated } \\
\text { carcinoma (15) }\end{array}$ & $11 / 4$ & 50.9 & 7.2 & 50.1 & 34.3 & 53.3 & $2 / 15$ & $6 / 15$ & 4.1 \\
\hline Anaplastic carcinoma (9) & $5 / 4$ & 64.7 & $52.2^{*}$ & $10.4^{*}$ & 65.6 & 33.3 & $2 / 9$ & $1 / 9$ & $25.3^{*}$ \\
\hline
\end{tabular}

${ }^{a}$ Considered as percentage of altered cases (including negative cases and overexpression: see Materials and Methods).

${ }^{*} p<0.05$. 

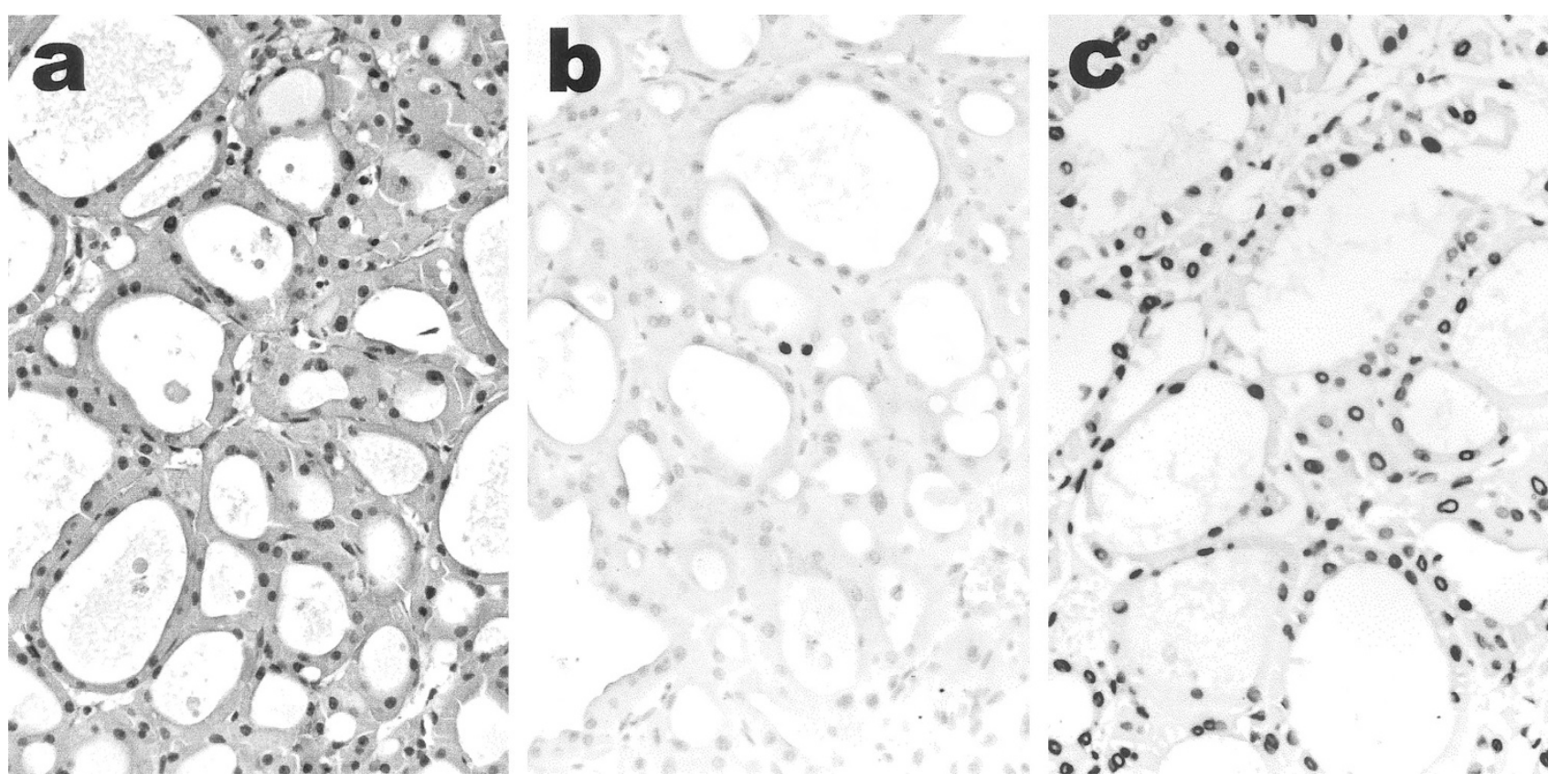

FIGURE 1. Oxyphilic thyroid adenoma. Cuboidal eosinophilic tumor cells (A, hematoxylin and eosin staining) show a low proliferation rate as detected by Ki-67 immunohistochemistry (B) but highly overexpress E2F-1 transcription factor (C).

therefore relied on a specific anti-E2F-1 monoclonal antibody to investigate its nuclear expression in thyroid tumors.

A variable percentage of E2F-1 immunoreactive cells was observed in all thyroid tumors studied and also in normal thyroid follicles. A surprisingly high mean expression of E2F-1 was observed in oxyphilic (Hurthle cell) tumors, irrespective of the benign or malignant nature and also of the histological type, because both classical oxyphilic (Hurthle cell) carcinoma and oxyphilic variant of papillary carcinoma showed E2F-1 overexpression. Oxyphilic adenomas and carcinomas contained E2F-1 protein in nearly $70 \%$ of their tumor cells, and oxyphilic papillary carcinomas also had a higher amount, as compared with nonoxyphilic counterparts. Interestingly, however, not all oxyphilic tumors had E2F-1 overexpression. Rare tumors had an E2F-1-positive cell percentage as low as $37 \%$. Moreover, E2F- 1 was less frequently overexpressed in cases of follicular tumors with focal oxyphilic features (not included in the present series). Based on these observations, E2F-1 overexpression seems to be the result of a particular metabolic status of these cells rather than to be related to the morphological oxyphilic changes. This hypothesis is also supported by the evidence that E2F-1 is not overexpressed in nonneoplastic cells having oxyphilic changes, such as in nodular goiter or Hashimoto thyroiditis. In nonoxyphilic tumors, E2F-1 protein expression had the expected progressive increase from normal thyroid to adenomas, well-differentiated carcinomas, and, finally, anaplastic carcinoma (range, 24-65.6\%). However, adenomas had a mean expression of $30.8 \%$, which was very close to that of follicular carcinomas (34.5\%), thus limiting the diagnostic role of E2F-1 protein expression.

E2F-1 overexpression was not paralleled by a high proliferative rate in oxyphilic tumors, nor by peculiar alterations of p27 or Rb. Ki-67 immunodetection showed mean proliferative indexes of $2.4 \%$ and $2.7 \%$ for malignant and benign oxyphilic tumors, respectively. p27 down-regulation paralleled that of follicular nonoxyphilic tumors, and $\mathrm{pRb}$ expression was retained in most oxyphilic tumors tested irrespective of the histological type, as also observed in the corresponding nonoxyphilic counterparts.

Therefore, although the expression of E2F-1 is expected to be a marker of cell cycle entering by the cell, for some unknown reasons, a fraction of E2F-1-positive oxyphilic cells is not scheduled for cell division. These tumors had in fact a low proliferative index, as detected by Ki-67 immunostaining, nor did these tumors show any correlation between E2F-1 overexpression and rapid growth or aggressive clinical behavior. Possibly, other functions are associated to E2F transcription factors in the group of oxyphilic tumors of the thyroid. Unique in the E2F transcription factor family, E2F-1 plays a pivotal role in cell cycle progression and/or in apoptosis, according to p53 function. In many tissues, the balance of proliferation versus apoptosis is maintained by variable E2F-1 levels, and a tissue-specific role of E2F-1 as an oncogene or a tumor suppressor gene has been proposed (37). In the same case series that are here represented, we recently described a peculiar pattern of genomic DNA fragmentation in oxyphilic lesions of the thyroid (33), which lead us to hypothesize the diffuse activation of apoptotic or aponecrotic processes in 


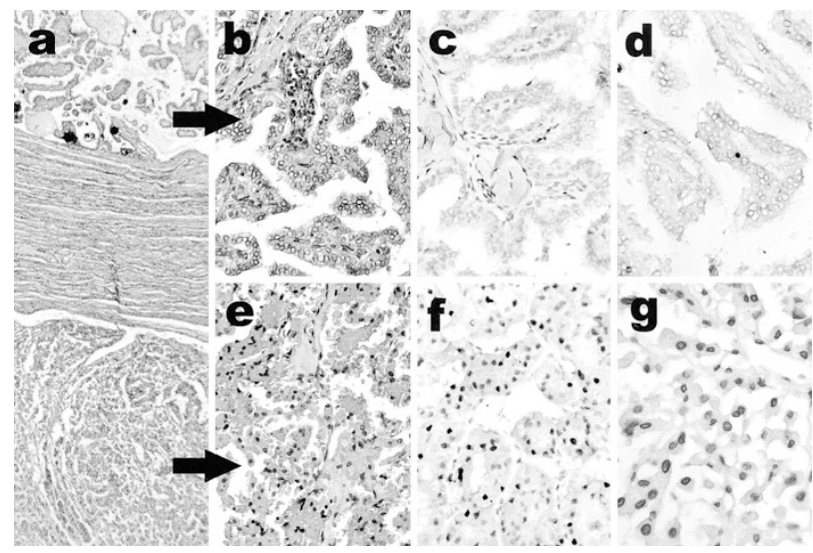

FIGURE 2. Different p27 and E2F-1 expression patterns in concurrent papillary and oxyphilic follicular carcinomas (same thyroid lobe; A). Papillary carcinoma cells (B) lack p27 immunoreactivity (otherwise preserved in stromal lymphocytes; C) and are virtually devoid of E2F-1 immunoreactivity (D). Oxyphilic carcinoma cells (E) maintain p27 expression (F) and strongly express E2F-1 protein (G).

mitochondrion-rich oxyphilic cells. The term aponecrosis has been proposed to describe a cell demise that shared dynamic, molecular, and morphologic features with both apoptosis and necrosis, adenosine triphosphate levels in the cells and the intensity of hypoxic injury being pivotal in determining apoptosis, necrosis, or aponecrosis (38). E2F-1 overexpression in oxyphilic tumors may represent the evidence of an activated signal of life or death switched on by particular metabolic conditions that in turn drive to aponecrotic processes rather than to cell cycle progression, in the presence of specific DNA damages. Lack of specific apoptotic markers (i.e., activated caspase-3 immunoreactivity) in the oxyphilic lesions with high DNA fragmentation was observed (33). As mitochondria are necessary for apoptosis initiation, their frequent alterations in oxyphilic tumors at both DNA and enzymatic levels $(39,40)$ could explain why the possible death signal triggered by E2F-1 could give raise to aponecrotic processes rather than to true apoptosis in these tumors. Future studies on in vitro models are needed to define the predominant functions of E2F-1 in oxyphilic tumor cell growth and differentiation and even to clarify the biochemical levels of its overexpression, possibly related to either increased transcription or reduced degradation.

In conclusion, E2F-1 is highly expressed in thyroid tumors, irrespective of their benign or malignant nature and of their proliferative status; in addition, oxyphilic tumors, among other histotypes, showed a marked overexpression, possibly linked to proapoptotic rather than proliferative signals in such neoplasms.

Acknowledgments: We thank Drs. G. Inghirami, A. Sapino, and R. Chiarle (University of Turin) for their suggestions and Rosalba Rosetto (University of Turin) for statistical advice.

\section{REFERENCES}

1. Nesland JM, Sobrinho Simoes M, Holm R, Sambade MC, Johannessen JV. Hurthle-cell lesions of the thyroid: a combined study using transmission electron microscopy, scanning electron microscopy, and immunohistochemistry. Ultrastruct Pathol 1985;8:269-90.

2. Tallini G. Oncocytic tumors. Virchows Arch 1998;433:5-12.

3. Watson RG, Brennan MD, Goellner JR, van Heerden JA, McConahey WM, Taylor WF. Invasive Hurthle cell carcinoma of the thyroid: natural history and management. Mayo Clinic Proc 1984;59:851-5.

4. Carcangiu ML, Bianchi S, Savino D, Voynick IM, Rosai J. Follicular Hurthle cell tumors of the thyroid gland. Cancer 1991;68:1944-53.

5. Rosai J, Carcangiu ML, De Lellis RA. Tumors of the thyroid gland. In: Atlas of tumor pathology. Washington, D.C.: Armed Forces Institute of Pathology; 1992. p. 161-82.

6. LiVolsi VA. Surgical pathology of the thyroid. Philadelphia: WB Saunders; 1990. p. 275-88.

7. Lazzereschi D, Sambuco L, Carnovale Scalzo C, Ranieri A, Mincione G, Nardi F, et al. Cyclin D1 and cyclin E expression in malignant thyroid cells and in human thyroid carcinomas. Int J Cancer 1998;76:806-11.

8. Wang S, Wuu J, Savas L, Patwardhan N, Khan A. The role of cell cycle regulatory proteins, cyclin D1, cyclin E, and p27 in thyroid carcinogenesis. Hum Pathol 1998;29:1304-9.

9. Wang S, Lloyd RV, Hutzler MJ, Safran MS, Patwardhan NA, Khan A. The role of cell cycle regulatory protein, cyclin D1, in the progression of thyroid cancer. Mod Pathol 2000;13: 882-7.

10. Erickson LA, Jin L, Goellner JR, Lohse C, Pankratz VS, Zukerberg LR, et al. Pathologic features, proliferative activity, and cyclin D1 expression in Hurthle cell neoplasms of the thyroid. Mod Pathol 2000;13:186-92.

11. Basolo F, Caligo MA, Pinchera A, Fedeli F, Baldanzi A, Miccoli P, et al. Cyclin D1 overexpression in thyroid carcinomas: relation with clinico-pathological parameters, retinoblastoma gene product, and Ki67 labeling index. Thyroid 2000;10:741-6.

12. Holm R, Nesland JM. Retinoblastoma and p53 tumour suppressor gene protein expression in carcinomas of the thyroid gland. J Pathol 1994;172:267-72.

13. Iuliano R, Trapasso F, Stella A, Le Pera I, Melillo RM, Bruni $\mathrm{P}$, et al. Pivotal role of the RB family proteins in in vitro thyroid cell transformation. Exp Cell Res 2000;260:257-67.

14. Anwar F, Emond MJ, Schmidt RA, Hwang HC, Bronner MP. Retinoblastoma expression in thyroid neoplasms. Mod Pathol 2000;13:562-9.

15. Erickson LA, Jin L, Wollan PC, Thompson GB, van Heerden J, Lloyd RV. Expression of p27kipl and Ki-67 in benign and malignant thyroid tumors. Mod Pathol 1998;11:169-74.

16. Resnick MB, Schacter P, Finkelstein Y, Kellner Y, Cohen O. Immunohistochemical analysis of p27/kip1 expression in thyroid carcinoma. Mod Pathol 1998;11:735-9.

17. Erickson LA, Yousef OM, Jin L, Lohse CM, Pankratz VS, Lloyd RV. p27kip1 expression distinguishes papillary hyperplasia in Graves' disease from papillary thyroid carcinoma. Mod Pathol 2000;13:1014-9.

18. Tallini G, Garcia-Rostan G, Herrero A, Zelterman D, Viale G, Bosari S, et al. Downregulation of p27KIP1 and Ki67/Mib1 labeling index support the classification of thyroid carcinoma into prognostically relevant categories. Am J Surg Pathol 1999;23:678-85.

19. Shi Y, Zou M, Farid NR, al-Sedairy ST. Evidence of gene deletion of p21 (WAF1/CIP1), a cyclin-dependent protein kinase inhibitor, in thyroid carcinomas. Br J Cancer 1996;74: 1336-41. 
20. Jones CJ, Shaw JJ, Wyllie FS, Gaillard N, Schlumberger M, Wynford-Thomas D. High frequency deletion of the tumour suppressor gene P16INK4a (MTS1) in human thyroid cancer cell lines. Mol Cell Endocrinol 1996;116:115-9.

21. Elisei R, Shiohara M, Koeffler HP, Fagin JA. Genetic and epigenetic alterations of the cyclin-dependent kinase inhibitors p15INK4b and p16INK4a in human thyroid carcinoma cell lines and primary thyroid carcinomas. Cancer 1998;83: 2185-93.

22. Papotti M, Torchio B, Grassi L, Favero A, Bussolati G. Poorly differentiated oxyphilic (Hurthle cell) carcinomas of the thyroid. Am J Surg Pathol 1996;20:686-94.

23. Qin XQ, Livingston DM, Kaelin WG Jr, Adams PD. Deregulated transcription factor E2F-1 expression leads to S-phase entry and p53-mediated apoptosis. Proc Natl Acad Sci U S A 1994;91:1918-22.

24. Wu X, Levine AJ. p53 and E2F-1 cooperate to mediate apoptosis. Proc Natl Acad Sci U S A 1994;91:3602-6.

25. Morgenbesser SD, Williams BO, Jacks T, DePinho RA. p53dependent apoptosis produced by Rb-deficiency in the developing mouse lens. Nature 1994;371:72-4.

26. Anwar F. The concurrent expression of retinoblastoma protein and E2F-1 family of transcription factors define a unique phenotype of Hurthle and Warthin-like variants of papillary carcinoma different from regular papillary carcinoma. Mod Pathol 2001;14:74A.

27. Lai R, Medeiros LJ, Wilson CS, Sun NC, Koo C, McCourty A, et al. Expression of the cell-cycle-related proteins E2F-1, p53, mdm-2, p21waf-1, and Ki-67 in multiple myeloma: correlation with cyclin-D1 immunoreactivity. Mod Pathol 1998;11: 642-7.

28. Lai R, Medeiros LJ, Coupland R, McCourty A, Brynes RK. Immunohistochemical detection of E2F-1 in non-Hodgkin's lymphomas: a survey of 124 cases. Mod Pathol 1998;11:45763.

29. Moller MB, Kania PW, Ino Y, Gerdes AM, Nielsen O, Louis $\mathrm{DN}$, et al. Frequent disruption of the RB1 pathway in diffuse large B cell lymphoma: prognostic significance of E2F-1 and p16INK4A. Leukemia 2000;14:898-904.

30. Yasui W, Naka K, Suzuki T, Fujimoto J, Hayashi K, Matsutani $\mathrm{N}$, et al. Expression of p27Kip1, cyclin E and E2F-1 in pri- mary and metastatic tumors of gastric carcinoma. Oncol Rep 1999;6:983-7.

31. Suzuki T, Yasui W, Yokozaki H, Naka K, Ishikawa T, Tahara E. Expression of the E2F family in human gastrointestinal carcinomas. Int J Cancer 1999;81:535-8.

32. Rabbani F, Richon VM, Orlow I, Lu ML, Drobnjak M, Dudas $\mathrm{M}$, et al. Prognostic significance of transcription factor E2F-1 in bladder cancer: genotypic and phenotypic characterization. J Natl Cancer Inst 1999;91:874-81.

33. Volante M, Papotti M, Gugliotta P, Migheli A, Bussolati G. Extensive DNA fragmentation in oxyphilic cell lesions of the thyroid. J Histochem Cytochem 2001;49:1003-11.

34. Bussolati G, Gugliotta P, Volante M, Pace M, Papotti M. Retrieved endogenous biotin: a novel marker and a potential pitfall in diagnostic immunohistochemistry. Histopathology 1997;31:400-7.

35. Adams JC. Biotin amplification of biotin and horseradish peroxidase signals in histochemical stain. J Histochem Cytochem 1992;40:1457-63.

36. Benedict WF, Lerner SP, Zhou J, Shen X, Tokunaga H, Czerniak $B$. Level of retinoblastoma protein expression correlates with p16 (MTS-1/INK4A/CDKN2) in bladder cancer. Oncogene 1999;18:1197-203.

37. Yamasaki L. Balancing proliferation and apoptosis in vivo: the Goldilocks theory of E2F/DP action. Biochim Biophys Acta 1999;1423:M9-15.

38. Formigli L, Papucci L, Tani A, Schiavone N, Tempestini A, Orlandini GE, et al. Aponecrosis: morphological and biochemical exploration of a syncretic process of cell death sharing apoptosis and necrosis. J Cell Physiol 2000;182:41-9.

39. Maximo V, Soares P, Rocha AS, Sobrinho Simoes M. The common deletion of mitochondrial DNA is found in goiters and thyroid tumors with and without oxyphilic cell change. Ultrastruct Pathol 1998;22:271-3.

40. Muller-Hocker J, Jacob U, Seibel P. Hashimoto thyroiditis is associated with defects of cytochrome-c oxydase in oxyphilic Askanazy cells and with the common deletion $(4,977)$ of mitochondrial DNA. Ultrastruct Pathol 1998;22: 91-100 